\title{
interROODA: mapeamento das interações individuais e interindividuais no ambiente virtual de aprendizagem ROODA *
}

\section{Patrícia B. Scherer Bassani*** Patricia Alejandra Behar ${ }^{* * *}$}

Resumo: Este artigo apresenta a modelagem e protótipo de uma ferramenta computacional para o mapeamento das interações, incorporada no ambiente virtual de aprendizagem ROODA. A ferramenta interROODA foi desenvolvida baseada numa concepção contrutivista-interacionista de aprendizagem, e tem por objetivo auxiliar o professor no processo avaliativo das atividades desenvolvidas no ambiente. A definição de um modelo para o mapeamento das interações envolveu três perspectivas de análise, enfocando as interações no ambiente, na disciplina e nas ferramentas, tanto em âmbito individual quanto coletivo.

Palavras-chave: educação a distância, ambiente virtual de aprendizagem, interação

interROODA: mapping the interactions in the virtual learning environment - ROODA

\begin{abstract}
This article considers the modeling and archetype of a computational tool to map the interactions in a virtual learning environment. This tool is called interROODA and was developed to help the professor in the evaluation process in distance learning classes. The definition of a model to the interaction's mapping involved three perspectives of analysis, focusing the interactions of the students in the virtual learning environment, in each subject/course and in different tools avaiable in system, such as chat and forum. The study had an individual and a collective approach.
\end{abstract}

Keywords: distance learning, virtual learning environment, interaction

\footnotetext{
* O presente trabalho foi realizado com o apoio da CAPES, entidade do Governo Brasileiro voltada para a formação de recursos humanos. Este trabalho tem apoio financeiro do Conselho Nacional de Desenvolvimento Científico e Tecnológico - CNPq, entidade governamental brasileira promotora do desenvolvimento científico e tecnológico.

"Doutoranda em Informática na Educação no Programa de Pós Graduação em Informática na Educação - UFRGS, professora do Curso de Licenciatura em Computação do Centro Universitário Feevale, patriciab@feevale.br

Doutora Patricia Alejandra Behar, Professora Adjunta da Faculdade de Educação e dos Programas de Pós-

Graduação em Educação e Informática na Educação, coordenadora do Núcleo de Tecnologia Digital aplicada a

Educação (NUTED), UFRGS.

V. $3 \mathrm{~N}^{\circ} 2$, Novembro, 2005
} 


\section{Introdução}

Os ambientes virtuais de aprendizagem vêm sendo utilizados de forma crescente para gerenciar aulas à distância e como instrumento de apoio pedagógico ao ensino presencial.

Nesta abordagem, entende-se que um ambiente virtual de aprendizagem (AVA) é caracterizado por um conjunto de ferramentas computacionais que permitem a criação e o gerenciamento de cursos à distância, potencializando processos de interação, colaboração e cooperação. Dessa forma, um AVA é um sistema computacional implementado por meio de uma linguagem de programação, que reúne, num único software (neste caso chamado de plataforma), possibilidades de acesso online ao conteúdo de cursos. Oferece, também, diversos recursos de comunicação/ interação/construção entre os sujeitos que participam do ambiente, como fórum de discussão, bate-papo ou ainda mural de recados. Logo, se por um lado os ambientes permitem a centralização de todas as informações referentes a um curso, por outro o gerenciamento deste grande fluxo de informações fica sob a responsabilidade de cada participante. O professor, neste contexto, se percebe diante de um emaranhado de informações, diluídas entre as várias ferramentas.

Portanto, entende-se que o mapeamento das interações que ocorrem nestes ambientes poderá auxiliar o professor, no que se refere ao acompanhamento do percurso de aprendizagem dos alunos no processo de construção/elaboração de conceitos. Além disso, pode oportunizar, ao aluno, a possibilidade de apropriação e acompanhamento do seu próprio processo de construção de conhecimento.

Este artigo apresenta o protótipo de uma ferramenta capaz de mapear as interações individuais e interindividuais em um ambiente virtual de aprendizagem, numa perspectiva quantitativa e qualitativa. Destaca-se que as interações individuais caracterizam-se pela interação sujeito $\leftrightarrow$ meio, e as interações interindividuais são caracterizadas pela interação entre $n$ sujeitos com o meio. Este estudo sustenta-se a partir de uma concepção construtivista-interacionista, onde se entende que a aprendizagem é um processo ao mesmo tempo individual e coletivo, ou ainda, "o processo de conhecimento ou processo de construção das estruturas cognitivas é radicalmente individual, realizado coletivamente" (Becker, 2001, p. 84).

Em diversos ambientes virtuais de aprendizagem pesquisados, como o TelEduc (Unicamp), e-Proinfo (MEC), AVA (Unisinos) e WebCT, existe a possibilidade de mapear as interações potencializadas pelas diversas ferramentas, numa perspectiva quantitativa, privilegiando número de acessos e quantidade de mensagens postadas. Entretanto, percebe-se que as pesquisas vêm delineando propostas de mapeamento que evidenciam aspectos qualitativos da interação, expressos pelo conteúdo das mensagens/discussões postadas pelos participantes de tais ambientes. Nesse sentido, em ambientes como AVA, TelEduc e WebCT é possível identificar com quem um determinado usuário interagiu e qual o conteúdo da mensagem, a partir de uma abordagem individual.

Com base no levantamento realizado e buscando ampliar o escopo das pesquisas em andamento, a ferramenta interROODA foi modelada com o objetivo de mapear os fluxos de interação numa perspectiva interindividual, de forma a possibilitar a visualização das interconexões das mensagens/contribuições individuais. 


\section{Modelagem da ferramenta interROODA}

A definição da ferramenta de mapeamento das interações, incorporada no ambiente virtual de aprendizagem ROODA, seguiu as seguintes etapas: levantamento de requisitos, análise, projeto, implementação, testes e implantação (Bezerra, 2002).

\subsection{Levantamento de requisitos}

O levantamento dos requisitos necessários para a definição da ferramenta proposta foi realizado a partir do estudo do conceito de interação nas perspectivas epistemológica e tecnológica, do levantamento sobre o "estado da arte" da área em questão, evidenciado a partir da análise de diversas ferramentas de mapeamento das interações disponíveis em alguns ambientes virtuais de aprendizagem, além dos estudos sobre avaliação e a análise das características do ambiente ROODA.

A partir dos estudos realizados, viu-se a necessidade de definir esta ferramenta a partir de um enfoque quantitativo e qualitativo. $O$ enfoque quantitativo da interação faz referência ao que é possível apresentar de informações quantificáveis, como número de acessos ao ambiente, número de acessos a determinadas atividades, quantidade de trabalhos enviados ou ainda o número de contribuições em determinada ferramenta. $\mathrm{O}$ enfoque qualitativo da interação prevê o mapeamento das contribuições individuais dos participantes e sua interconexão com as contribuições de outros participantes, caracterizando, numa perspectiva piagetiana (1973), a dinâmica de trocas.

Dessa forma, entende-se que uma ferramenta para o mapeamento das interações em um ambiente virtual de aprendizagem deve compreender 2 (dois) módulos complementares:

a) acompanhamento de acesso e freqüência;

b) trocas interindividuais.

A ferramenta interROODA segue as características do ambiente ao qual está sendo incorporada. No ambiente ROODA, as funcionalidades (ou ferramentas) podem ser classificadas sob duas perspectivas: vínculo com o sistema e relação topológica, que é baseada na disposição dos links para acesso às funcionalidades no ambiente, a partir da concepção de espaço (Behar, 2005).

$\mathrm{O}$ vínculo com o sistema pode ser geral ou específico. $\mathrm{O}$ primeiro refere-se às funcionalidades que estão disponíveis a todos usuários de forma independente às disciplinas cursadas. O vínculo específico refere-se àquelas funcionalidades que podem ser habilitadas (ou não) pelo professor para uso específico em determinada disciplina.

A relação topológica implica na localização da funcionalidade no ambiente. As funcionalidades estão subdivididas em 3 áreas: menu superior, abas laterais e área de trabalho. $\mathrm{O}$ menu superior é fixo e as funcionalidades nele posicionadas estão sempre à disposição do usuário, como mostra a figura 1. Nas abas laterais encontram-se as funcionalidades que podem ser habilitadas ou não pelo professor quando do cadastro da disciplina. A área de trabalho é reservada para as telas características de cada funcionalidade, além do mural e lembretes. 


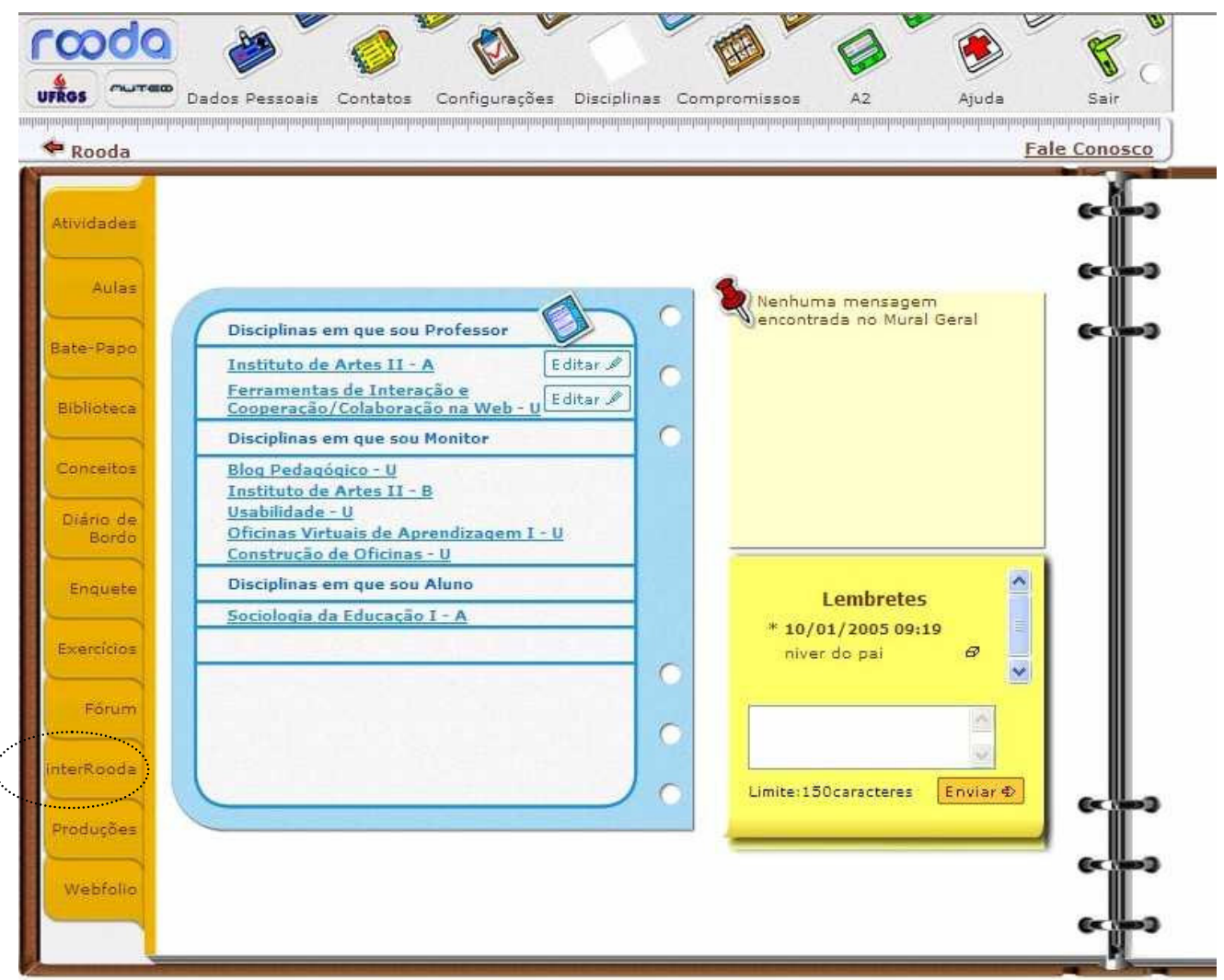

Figura 1: Interface do ambiente ROODA e relação topológica da ferramenta interROODA

A funcionalidade interROODA encontra-se assim classificada:

a) vínculo geral: o módulo de acompanhamento de acesso e freqüência possui habilitação geral, permitindo, a cada usuário, o acesso a todas as suas interações no ambiente ROODA, incluindo acessos por disciplina e por ferramenta;

b) vínculo específico: além da habilitação geral, o módulo de acesso e frequiência também possui vínculo específico, automaticamente habilitado, de forma a possibilitar que o usuário tenha acesso as suas interações no âmbito de determinada disciplina, e possibilitar ao professor o acesso às interações de seus alunos. O módulo de trocas interindividuais somente pode ser acessado quando habilitado pelo professor.

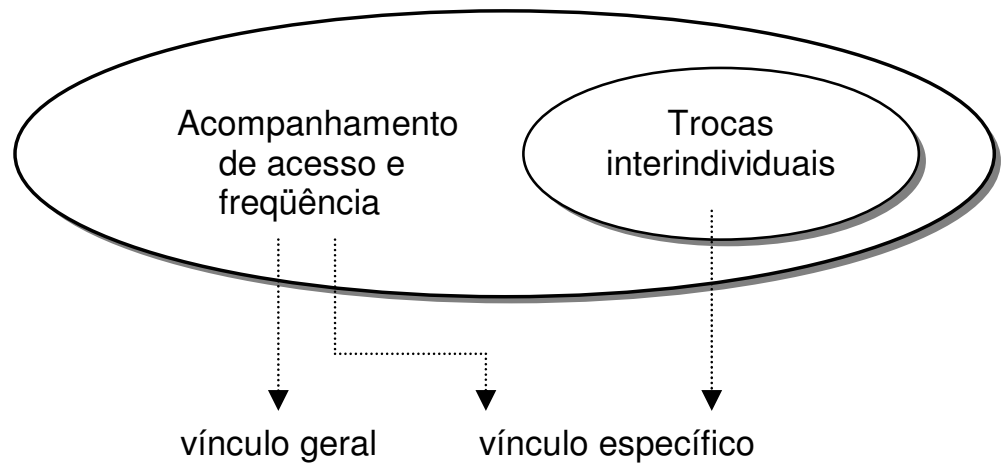

Figura 2 - Relação da funcionalidade interROODA 


\subsection{Análise, Projeto e Implementação}

A modelagem da ferramenta interROODA segue o paradigma de orientação a objetos e foi realizada utilizando a notação UML. A UML é uma linguagem visual para modelar sistemas orientados a objetos, ou seja, uma linguagem que permite representar os conceitos do paradigma de orientação a objetos por meio de elementos gráficos. A visualização do sistema é feita por meio de diagramas. O diagrama de casos de uso apresenta "uma representação das funcionalidades externamente observáveis do sistema e dos elementos externos ao sistema que interagem com ele" (Bezerra, 2002). Este modelo é composto por casos de uso, atores e os relacionamentos entre estes. Um caso de uso (use case) representa as interações entre os agentes externos e o sistema, sem considerar o comportamento interno do sistema. $\mathrm{O}$ ator é qualquer elemento externo que interage com o sistema, a partir do envio e/ou recebimento de informações.

$\mathrm{Na}$ modelagem da ferramenta interROODA, foi possível identificar e documentar os seguintes atores:

a) Professor: tem acesso a todas as interações dos participantes de uma disciplina;

b) Aluno: visualiza suas interações no ambiente, numa perspectiva individual e interindividual;

c) Ambiente ROODA: sistema que mantém todas informações sobre os acessos dos participantes e armazena todas as mensagens/contribuições individuais.

A figura 3 apresenta o diagrama de casos de uso da ferramenta interROODA:

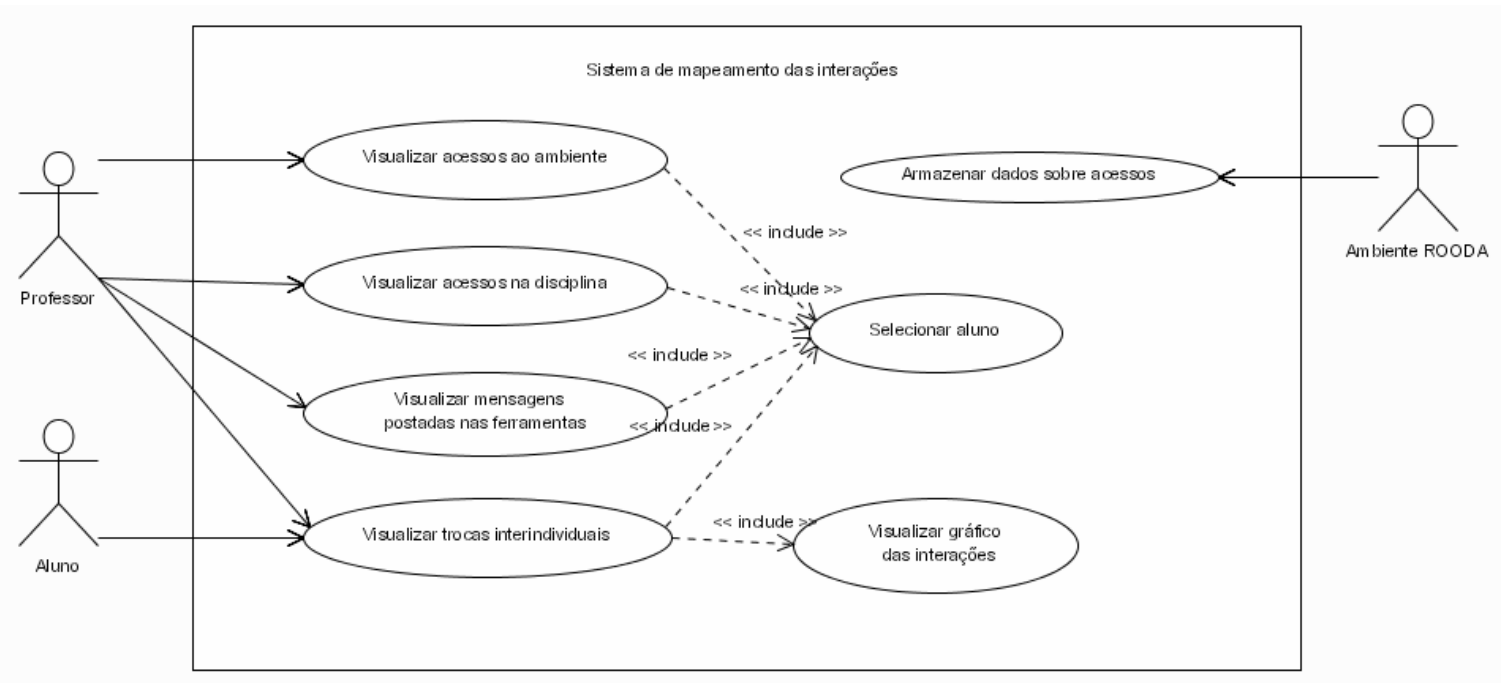

Figura 3 - Diagrama de casos de uso

Foi necessária a criação de tabelas específicas para armazenamento de dados referentes aos acessos, além de modificações em tabelas já existentes. O modelo proposto foi implementado utilizando a linguagem de programação PHP. 


\section{Protótipo da ferramenta interROODA}

Conforme dito anteriormente, a ferramenta interROODA é composta por dois módulos complementares para o mapeamento das interações. Estes se encontram especificados a seguir.

\subsection{Acompanhamento de acesso e freqüiência}

Apresenta dados quantitativos referentes à presença no ambiente ROODA, envolvendo acessos ao ambiente, aos cursos/disciplinas e às funcionalidades disponíveis, participação nas atividades individuais e coletivas, além de acesso aos textos/contribuições postadas em cada ferramenta.

Este módulo possui interfaces diferenciadas para vínculo geral e vínculo específico.

As opções disponíveis para consulta, quando vínculo geral, são:

a) acessos ao ambiente ROODA: apresenta o número de vezes que o usuário acessou o ambiente ROODA e número de horas de navegação (por período ou geral);

b) acessos por disciplina: relaciona o número de vezes que o sujeito acessou uma determinada disciplina (por período ou geral);

c) acessos por ferramenta: apresenta o número de vezes que um determinado sujeito acessou cada uma das ferramentas (por período ou geral), oportunizando a visualização das mensagens postadas.

A figura 4 apresenta a tela inicial do módulo de acompanhamento de acesso e freqüência.

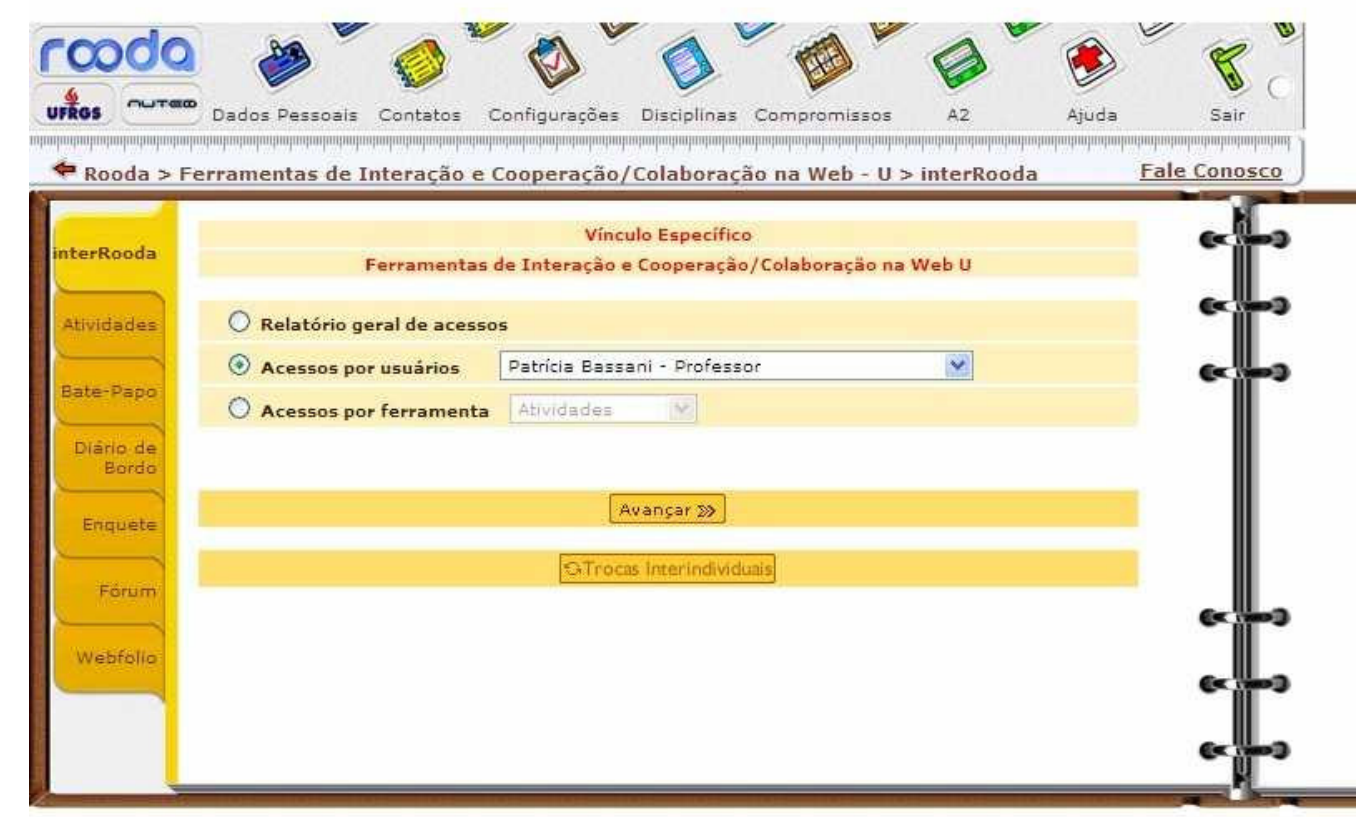

Figura 4 - Acompanhamento de acesso e freqüência - tela inicial

No vínculo específico foram implementadas diferentes visões para aluno e professor. O aluno visualiza apenas seus acessos e suas mensagens, enquanto, ao professor, é disponibilizado a visualização dos acessos e das mensagens de todos alunos da turma, conforme figura abaixo. 


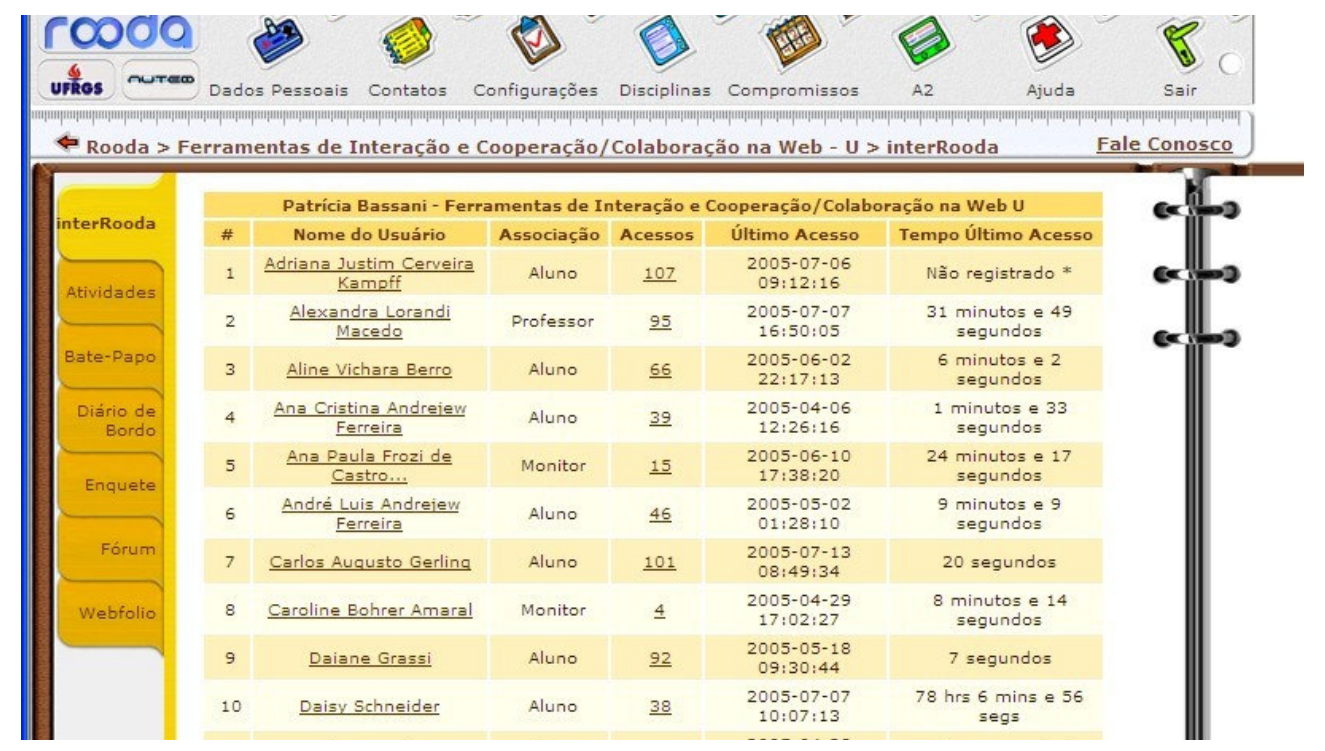

Figura 5 - Relatório geral de acessos - visão do professor

O professor tem acesso às mensagens postadas por determinado aluno a partir da opção acessos por ferramenta, conforme figura 6 .

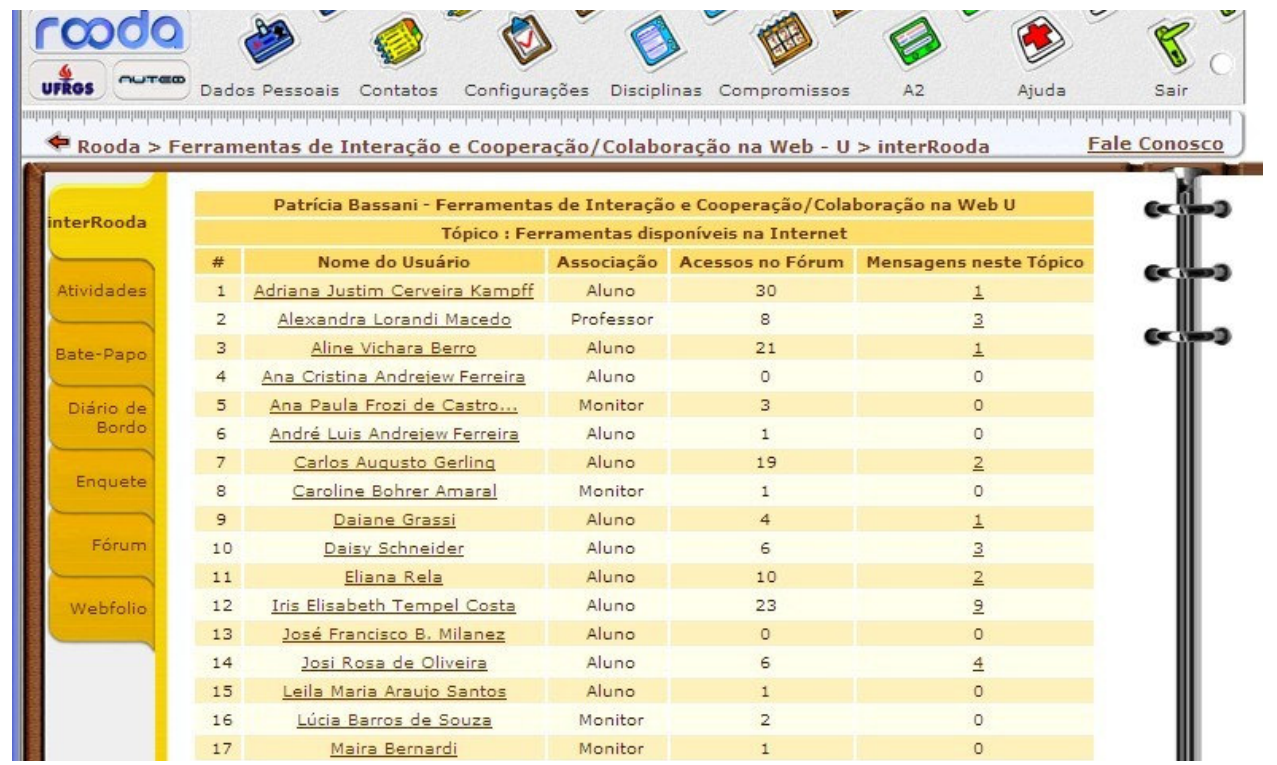

Figura 6 - Acessos por ferramenta

\subsection{Trocas interindividuais}

Como foi dito anteriormente, a concepção da ferramenta foi baseada nas idéias de Piaget, em relação às interações individuais e interindividuais. Conforme este autor (1973, p. 119), "toda ação ou reação de um indivíduo, avaliado segundo sua escala pessoal, repercute necessariamente sobre os outros indivíduos (...) Cada ação provocará, pois, por parte dos outros indivíduos uma ação de volta". Piaget (1973) afirma, ainda, que em toda sociedade existe uma escala de valores, que podem ser provenientes de várias fontes, interesses/gostos individuais, valores coletivos impostos (por exemplo: religião/moda) ou regras morais/jurídicas. Sendo assim, todas as ações/trabalhos/serviços, atual ou virtualmente, realizados por um sujeito é suscetível de ser avaliado e comparado segundo algumas relações de valores, que constituem uma 
escala de valores. Dessa forma, a existência de escalas de valores traduz-se por uma valorização recíproca das ações/serviços, que pode ser positiva ou negativa.

O mapeamento das trocas interindividuais busca refletir a dinâmica das interações que se constituem entre os sujeitos participantes de um ambiente virtual de aprendizagem. Entende-se que a partir da visualização do fluxo das mensagens torna-se possível o acompanhamento do processo de uma discussão/troca de idéias em âmbito individual e coletivo.

Dessa forma, quando o módulo referente às trocas interindividuais for habilitado na disciplina, tanto professor quanto aluno tem acesso ao fluxo das trocas de mensagens. Destaca-se que este módulo contempla, inicialmente, apenas as interações potencializadas pela funcionalidade Fórum de Discussão, do ambiente ROODA.

O mapeamento da rede de interações, evidenciada a partir das trocas interindividuais, busca as interações de um determinado aluno em um determinado tópico do fórum de discussão da disciplina cursada no ambiente ROODA. O sistema analisa as mensagens postadas e as classifica em enunciado ou citação. Considerando um fórum organizado hierarquicamente em modelo de árvore, entende-se como enunciado, a mensagem-pai, e citação, as mensagens a ela vinculadas.

A figura 7 apresenta o relatório de contribuições de um determinado aluno.

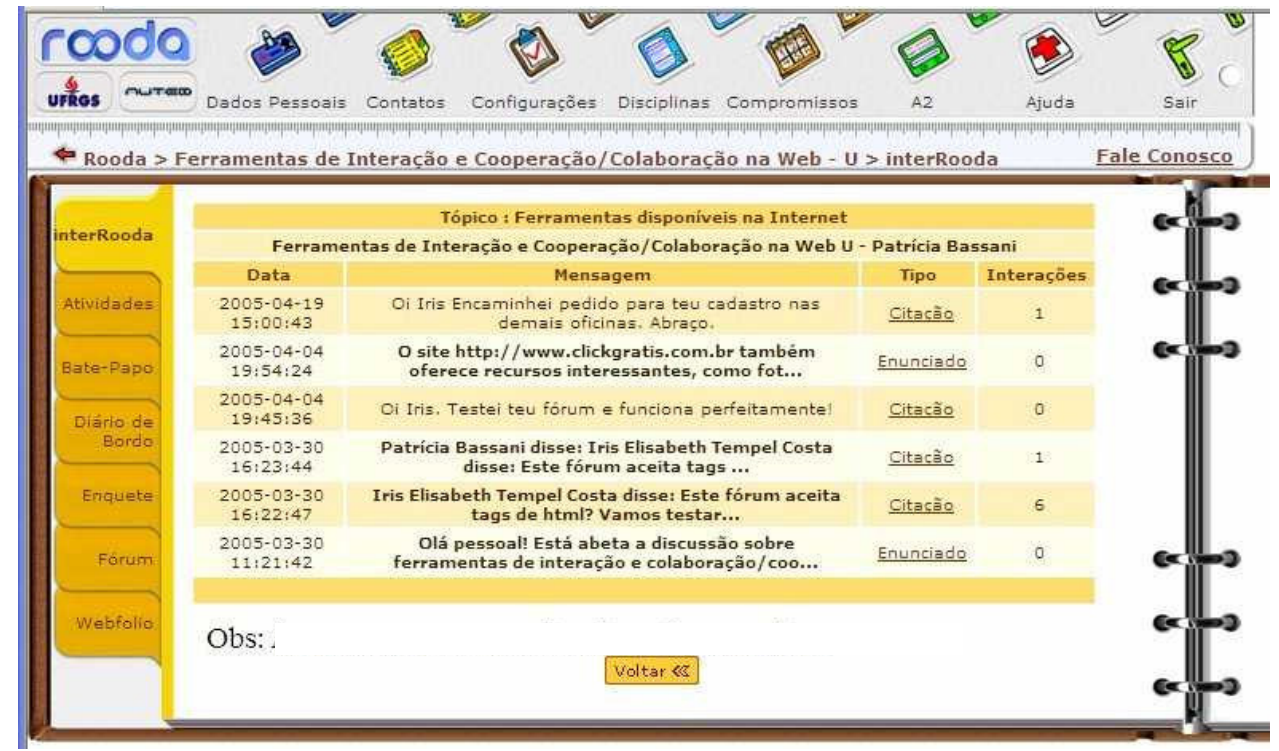

Figura 7 - Mapeamento das trocas interindividuais

O mapeamento das trocas interindividuais permite, ao professor, o acesso às mensagens postadas pelo aluno no tópico. A ferramenta apresenta, também, o número de interações decorrentes da mensagem, o que possibilita a visualização do gráfico das interações, representado pela figura 8 . Este gráfico consiste na apresentação do conteúdo de todas mensagens vinculadas, permitindo a visualização das contribuições de determinado aluno dentro do contexto que lhe deu origem. De fato, o gráfico das interações representa um recorte das interações que se dão no fórum de discussão, apresentando todas as mensagens relacionadas à mensagem selecionada.

Entende-se que esta proposta oportuniza indícios significativos para a auto-avaliação e para a avaliação formativa, permitindo uma análise da reação do grupo frente à mensagem, evidenciada a partir da continuidade (ou não) das trocas/discussão. Dessa forma, uma avaliação baseada nas interações entre os participantes de um curso a 
distância, vem ao encontro desta nova perspectiva avaliativa, em que se busca avaliar o produto no processo (Vasconcellos, 1998).

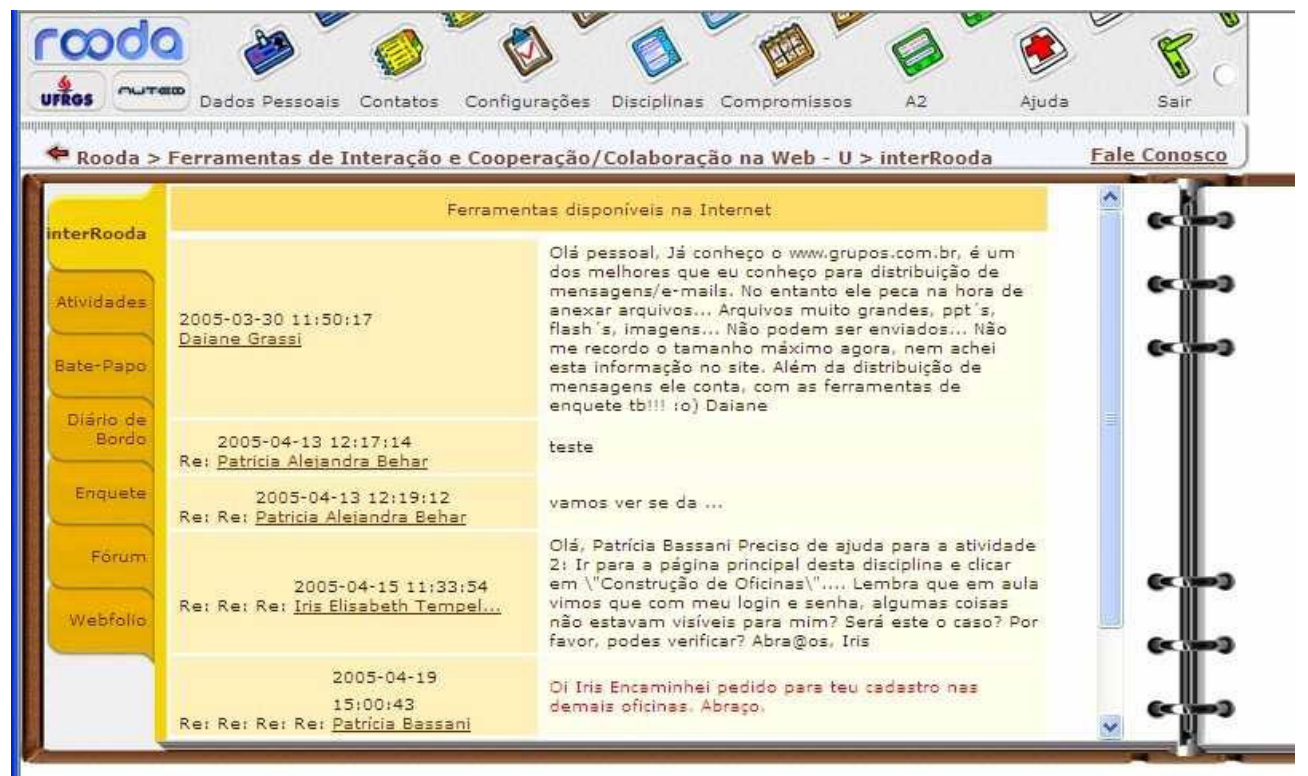

Figura 8 - Gráfico das interações

\section{Considerações finais}

A definição da ferramenta interROODA envolveu um resgate teórico sobre o conceito de interação nas perspectivas epistemológica e tecnológica, o delineamento dos conceitos de aprendizagem e avaliação, além do levantamento do "estado da arte" do problema em questão, a fim de destacar pontos referenciais/conceitos-chave para a modelagem das interações em ambiente virtual de aprendizagem.

Os testes com o protótipo foram realizados a partir das interações produzidas na disciplina Oficinas Virtuais de Aprendizagem, do curso de Doutorado em Informática na Educação da UFRGS, durante o primeiro semestre de 2005. Foram coletados os dados para fins de avaliação e testes da ferramenta. Ressalta-se que este artigo não tem por objetivo apresentar os resultados, mas detalhar o protótipo da ferramenta. $\mathrm{O}$ detalhamento desta análise encontra-se em processo de elaboração (Bassani, 2004).

Percebe-se que o módulo de acesso e freqüência permite uma avaliação baseada em dados quantitativos, além de possibilitar um rápido acesso ao conteúdo das mensagens postadas. Entretanto, este conteúdo é avaliado fora do contexto no qual teve origem. Outro aspecto relevante é de que a avaliação das contribuições é feita numa perspectiva individual. Este módulo justifica-se, uma vez que, para haver interação, torna-se necessário a participação. A partir dos dados apresentados neste módulo, entende-se que:

a) cada aluno/participante de um curso efetivado a partir do ambiente virtual de aprendizagem ROODA poderá acompanhar sua frequiência;

b) a partir da verificação quantitativa de acesso, o professor poderá buscar estratégias para o engajamento de alunos "não participativos". Sugere-se que os dados apresentados neste módulo não devem ser utilizados com fins avaliativos, mas como aspectos balizadores da participação e presença do aluno.

Por outro lado, entende-se que a visualização da rede de interações, possibilitada pelo módulo de trocas interindividuais, permite um novo olhar sobre o processo de avaliação em ambientes virtuais de aprendizagem. Esta nova perspectiva avaliativa busca contemplar o produto no processo, ou seja, permite uma avaliação do conteúdo produzido/assimilado pelo aluno a partir das trocas. 
Dessa forma, a ferramenta interROODA contribui para o processo avaliativo no ambiente virtual de aprendizagem ROODA, uma vez que oportuniza a visualização das mensagens/contribuições postadas por um participante de uma disciplina de forma individual ou numa perspectiva coletiva, a partir do mapeamento das trocas interindividuais. Entretanto, a análise dos resultados apresentados depende do paradigma orientador da prática do professor.

Atualmente, novos estudos vêm sendo realizados buscando formas de automatizar partes deste processo de análise. Está-se trabalhando num modelo de categorização das mensagens postadas no fórum, de forma a possibilitar, também, a análise do conteúdo. Entende-se que a categorização dos conteúdos permitirá, ao professor, distinguir contribuições relacionadas ao conhecimento específico em estudo daquelas relacionadas, por exemplo, a aspectos de organização de tarefas e expressão de sentimentos.

\section{Referências}

BASSANI, Patrícia B. Scherer. Modelagem das interações em ambiente virtual de aprendizagem. Porto Alegre: PPGIE/UFRGS, 2004. Proposta de Tese de Doutorado. BECKER, Fernando. Educação e construção do conhecimento. Porto Alegre: Artmed Editora, 2001.

BEHAR, Patricia Alejandra et al. A categorização das funcionalidades do ambiente virtual ROODA. RENOTE: revista novas tecnologias na educação. Porto Alegre: UFRGS, Centro Interdisciplinar de Novas Tecnologias na Educação, mai. 2005.

BEZERRA, Eduardo. Princípios de análise e projeto de sistemas com UML. Rio de Janeiro: Campus, 2002.

PIAGET, Jean. Estudos Sociológicos. Rio de Janeiro: Forense, 1973.

VASCONCELLOS, Celso. Avaliação da aprendizagem: práticas de mudança: por uma práxis transformadora. $3^{\mathrm{a}}$ ed. São Paulo: Libertad, 1998. 